\title{
Pattern and categorisation of neurosurgical emergencies
}

\author{
Dilip K. Kulkarni
}

\begin{abstract}
Usually most of the neurosurgical emergencies have to be operated within 24 hours to 72 hours for better outcome in patient point of view. Depending upon the pattern of neurosurgical conditions, if we categorise these emergency surgeries, taking into consideration the priority of performing the operations the mortality and morbidity will reduce. This will help in better usage of operating room time (OR Time), hospital resources and at the same time not affecting the elective surgical operations.
\end{abstract}

Key words: Categorisation, emergency, neurosurgery

Emergency surgery is usually performed after clinically assessing the patient within $24 \mathrm{~h}$ or in $<72 \mathrm{~h}$. Most of the emergency cases of neurosurgery fall into this category. If surgery is delayed, it can lead to increase in morbidity and mortality.

If we categorise the emergency neurosurgical procedures on a priority basis depending on the pattern of the neurosurgical conditions the patient outcome improves and will enhance the satisfaction among the patient and also surgical team. The categorisation will help to properly allocate the operating rooms and other hospital resources without affecting the elective surgical procedures. There will be an overall improvement in hospital emergency services.

The pattern of emergency neurosurgical procedures can be classified as follows: ${ }^{[1]}$

Department of Anaesthesiology and Intensive Care, Nizam's Institute of Medical Sciences, Hyderabad, Telangana, India

Address for correspondence:

Dr. Dilip K. Kulkarni, Department of Anaesthesiology and Intensive

Care, Nizam's Institute of Medical Sciences, Hyderabad - 500038 ,

Telangana, India.

E-mail:dilipkum@gmail.com

\begin{tabular}{|l|l|}
\hline \multicolumn{2}{|c|}{ Access this article online } \\
\hline Quick Response Code: & Website: \\
\hline & www.jnaccjournal.org \\
\cline { 2 - 3 } & \\
\hline & \\
\hline
\end{tabular}

1. Traumatic injuries

2. Non-traumatic pathological conditions.

\section{TRAUMATIC INJURIES}

Head injury

1. Skull fracture: Skull base, linear skull vault and depressed skull vault fractures

2. Intracranial injury: Diffuse, focal: contusion or haematoma (extradural, subarachnoid, subdural and intracranial)

3. Penetrating injuries.

Spinal injury

1. Fracture cervical vertebrae or dislocation

2. Fracture thoracic vertebrae or dislocation

3. Fracture lumbar vertebrae or dislocation

4. Spinal cord injury: Complete, incomplete (central cord syndrome, anterior cord syndrome, Brown-Sequard, spinal cord injury without radiologic abnormality).

\section{Polytrauma}

1. Polytrauma patient unstable neurologically for urgent neurosurgical surgery

2. Polytrauma patient stable neurologically for urgent

This is an open access article distributed under the terms of the Creative Commons Attribution-NonCommercial-ShareAlike 3.0 License, which allows others to remix, tweak, and build upon the work non-commercially, as long as the author is credited and the new creations are licensed under the identical terms.

For reprints contact: reprints@medknow.com

How to cite this article: Kulkarni DK. Pattern and categorisation of neurosurgical emergencies. J Neuroanaesthesiol Crit Care 2017;4:S6-8. 
neurosurgical surgery

3. Polytrauma patient unstable neurologically for urgent non-neurosurgical surgery

4. Polytrauma patient stable neurologically for urgent non-neurosurgical surgery.

\section{NON-TRAUMATIC PATHOLOGICAL CONDITIONS}

\section{Cranial}

1. Infections: Abscess, empyema

2. Vascular: Aneurysms, arteriovenous malformation, pituitary apoplexy

3. Non-traumatic intracranial haemorrhage, chronic subdural haematoma

4. Neoplastic: Primary and secondary

5. Hydrocephalus of any aetiology.

\section{Spinal}

1. Congenital: Meningocele, meningomyelocele

2. Infections: Spinal epidural abscess or empyema, cauda equina syndrome, cervical myelopathy

3. Vascular: Spinal epidural haematoma

4. Neoplastic: Extradural: vertebral tumours (primary or metastases)

5. Intradural: Extramedullary (e.g., meningioma or neurofibroma).

The neurosurgical emergencies can be categorised depending upon the urgency of doing surgery as follows: ${ }^{[2]}$

1. Immediate life-threatening - The patient is at risk of immediate loss of life and not responding to resuscitative measures

2. Life threatening-The patient is at risk of immediate loss of life and but responding to resuscitative measures

3. Organ threatening - Patient is haemodynamically and physiologically stable. However, there is a risk of immediate loss of organ

4. Non-critical,emergent-Patientishaemodynamically and physiologically stable but untreated the condition will deteriorate

5. Non-critical, non-emergent, urgent - Patient is haemodynamically and physiologically stable, and the condition may deteriorate

6. Semi-urgent, not stable for discharge - Patient is haemodynamically and physiologically stable and the condition may not deteriorate. However, the patient cannot be discharged.

Examples of neurosurgical procedures requiring urgent operative management are given in Table 1.

Emergency neurosurgeries are a major component of the workload of neurosurgeons. Proper planning for the predictable surgical workload for this specialty and to allocation of the necessary operating theatre (OR) time which includes immediate access to ORs for the most urgent emergency surgery is important. The planning should include the workload, workforce and resources. It must take into account the unique threats to life, limb and organ function faced by the patients. These risks increase with the passage of minutes or hours.

The advantages of categorisation of emergency surgery are numerous. It will result in benefits in three main areas:

1. Clinical performance is improved by reducing the morbidity and mortality. Which in turn improves the predictability of access to surgery, better provision of focused training in emergency surgery,

Table 1: Priorities for emergency neurosurgeries

\begin{tabular}{lcl}
\hline Priority and urgency & Time limit & Emergency conditions \\
\hline Immediate life-threatening & $<15 \mathrm{~min}$ & $\begin{array}{l}\text { Any intracranial conditions with imminent risk of 'coning', } \\
\text { acute extradural haematoma }\end{array}$ \\
Life threatening & $<1 \mathrm{~h}$ & $\begin{array}{l}\text { Subdural, intracerebral haematoma, penetrating injuries and } \\
\text { post-operative deterioration, polytrauma patient unstable } \\
\text { neurologically for urgent neurosurgical surgery }\end{array}$ \\
Organ threatening & $<4 \mathrm{~h}$ & $\begin{array}{l}\text { Spinalcord compression by trauma or tumours, cauda equina, } \\
\text { intracranial tumours causing critical raised intracranial } \\
\text { pressure, skull fractures. Blocked shunt, polytrauma patient } \\
\text { unstable neurologically for urgent non-neurosurgical surgery }\end{array}$ \\
& & $\begin{array}{l}\text { Cerebral abscess, pituitary apoplexy, ruptured } \\
\text { meningomyelocele }\end{array}$ \\
Non-critical, emergent & $<8 \mathrm{~h}$ & $\begin{array}{l}\text { Hydrocephalus, chronic subarachnoid haematoma, } \\
\text { aneurysms, AVMs, polytrauma patient stable neurologically } \\
\text { for urgent neurosurgical surgery }\end{array}$ \\
Non-critical, non-emergent, urgent & $<24 \mathrm{~h}$ & $\begin{array}{l}\text { Disc herniations with impending cauda equina syndrome, } \\
\text { posterior fossa mass lesions }\end{array}$ \\
\hline
\end{tabular}

AVMs=Arteriovenous malformations 
and adjustments to sub-specialisation.

2. Service management improves the emergency theatre utilisation, reduces elective surgery cancellations, reduces after-hours surgeries, reduces in length-of-stay, and reduces delays in performing emergency surgeries.

3. Resource utilisation causes improved availability of Intensive Care Units and high dependency units and improved use of radiology and pathology investigations.

To conclude by defining the pattern of neurosurgical conditions and categorising them according to priority and operating will improve the patient outcome, better utilisation of OR time, proper use of hospital resources and workforce. The elective theatre lists also will not be affected.

\section{Financial support and sponsorship} Nil.

Conflicts of interest

There are no conflicts of interest.

\section{REFERENCES}

1. Semple P, Malan BJ. Emergency presentation of neurosurgical conditions neurosurgical emergencies. CME 2013;31:75-9.

2. MacLellan D. Emergency Surgery Guidelines 2009. Report No.: GL2009_009. North Sydney: NSW Department of Health; 2009. p. 44. Available from: http://www.health.nsw. gov.au/policies/gl/2009/pdf/GL2009_009.pdf. [Last cited on 2009 Jun 23]. 